\title{
Changing the meaning of peer-to-peer? Exploring online comment spaces as sites of negotiated expertise
}

\author{
Marie-Claire Shanahan
}

\begin{abstract}
This study examines the nature of peer-to-peer interactions in public online comment spaces. From a theoretical perspective of boundary-work and expertise, the comments posted in response to three health sciences news articles from a national newspaper are explored to determine whether both scientific and personal expertise are recognized and taken up in discussion. Posts were analysed for both explicit claims to expertise and implicit claims embedded in discourse. The analysis suggests that while both scientific and personal expertise are proffered by commenters, it is scientific expertise that is privileged. Those expressing scientific expertise receive greater recognition of the value of their posts. Contributors seeking to share personal expertise are found to engage in scientisation to position themselves as worthwhile experts. Findings suggest that despite the possibilities afforded by online comments for a broader vision of what peer-to-peer interaction means, this possibility is not realized.
\end{abstract}

Increasing calls for public engagement in science and the ever growing accessibility of information has lead to important questions about whom is to be considered expert and whose contributions are to be taken seriously when public policy, discussion and decision making involves science and scientists. Traditional boundaries marked those with scientific credentials as experts and those without as nonexperts. In pre-Web 2.0 science, this boundary also defined who had contributory access to creating scientific knowledge as well as those who had interactional access - the ability to read, comment on and discuss scientific findings. Interactive public discussion of scientific research existed primarily in letters to the editor and peer-reviewed commentaries published in scientific journals. Access to these journals usually requires a personal subscription or access to an institutional subscription generally only afforded by a position within a research or academic institution. Outside of academic journals, public reports of science often followed a public understanding model characterized by one-way communication with, for example, science journalists acting as intermediaries, communicating expert scientific findings to nonexperts outside of science.

Collins and Evans ${ }^{1}$ assert, however, that a new view of expertise is needed to a) account for the contributions that individuals without scientific credentials can make to scientific knowledge and $b$ ) to better describe the lack of expertise that scientists hold outside their focus area. Instead of a horizontal line between those with scientific credentials and those without, they propose a vertical boundary marking those with contributory expertise from those without. This includes scientists working in their area of expertise and individuals outside of traditional science who have developed practical expertise that allows them to contribute to building new knowledge, for example, farmers, AIDS activists, and cancer patients whose personal experience offers ways of understanding that cannot be accounted for in laboratory science.

The public read-write capabilities of current internet communications have the potential to support the participation and recognition of these non-scientific experts. They allow individuals, regardless of scientific credentials, to engage in two-way communication to a greater degree and in a more immediate way. In many cases, such as the comment spaces provided by both blogs and traditional news sites, this participation is also anonymous. There are no formal qualifications needed to contribute and the only 
expertise that can be recognized is that which people ascribe to themselves either explicitly or implicitly. This opens up new possibilities for peer to peer communications. For example, communications between scientific peers may take place in the public view and, if there is greater recognition of personal expertise, there are possibilities for peer-to-peer interactions between experts, regardless of their status as scientific or personal experts. This would be a fundamental change in scientific communication.

Given the peer-to-peer possibilities of the open and anonymous nature of these spaces, my goal in this study is to explore whether Collins and Evans vertical expertise boundary is evident in the discourse of public comments related to science reporting or whether participants with apparent science qualifications engage in boundary work to maintain the traditional line between those with science qualifications and those without. Specifically, I ask whether the contributory and interactional contributions of those who claim non-scientific expertise are recognized as expertise and taken up in conversation by the experts and non-experts present in one type of online forum.

This study examines the public comments section of three science-related news articles appearing in a Canadian national newspaper. These articles address fields in which there is a reasonable possibility of individuals outside of science having contributory or interactional expertise. Two articles describe drug and treatment research and the other, epidemiological research. This study examines explicit claims to expertise (direct statement of expertise) through general thematic analysis (generic qualitative analysis) as well as implicit claims to expertise through linguistic discourse analysis - through examining syntax and grammar choices that implicitly signal claims to expertise.

\section{Context}

\section{Expertise}

Evans and Collins ${ }^{2}$ make the claim that one of the most important outcomes of science and technology studies has been the recognition that knowledge and expertise also exist outside of mainstream scientific communities. Despite this academic recognition, however, conventional boundaries between scientific insiders and scientific outsiders remain salient in most public discussions of science. As noted above, Collins and Evans attempt to draw a new boundary between those with contributory expertise and those without, regardless of scientific training or certification. Contributory expertise refers to experience and knowledge that would allow an individual to contribute to the construction of new knowledge in a particular field. In most areas of science this includes a select group of researchers who have completed extensive training and research in the area. In some situations, there are also individuals outside of science with comprehensive personal knowledge and experience who may be able to contribute to knowledge generation. Expertise then becomes defined by those who have sustained experience with some aspect of an issue or area of study. Specialist scientists retain their rightful claims to this expertise but the category is opened to those who have sustained experience due to their life experience, diagnoses, and other experience outside of mainstream science. ${ }^{3}$ This view notably recognizes that all experience, and therefore all expertise, is specialized and that in most cases it excludes scientists working or speaking outside of their research area. ${ }^{4}$

As suggested by the connection between expertise and experience, the development of expertise is a sociocultural project. It is, in many cases, an enculturation and linguistic socialisation and therefore something that does not exist as a dichotomy but instead as an inexact continuum. Evans and Collins suggest such a continuum in a Periodic Table of Expertises. ${ }^{5,6,7}$ They describe a range of socially acquired knowledge (for which experience is a necessary but not sufficient condition) that can be mapped to categories of expertise. On one extreme rests those with contributory expertise, with knowledge and experience sufficient to contribute to the construction of new knowledge in a particular field. On the other rests those with absolutely no knowledge of the field under consideration: those who would approach any research reports using only ubiquitous reading and reasoning skills. If an individual begins to learn about a field they may progress to acquiring some isolated facts (often those available in the media and activist advertising campaigns) and then toward a degree of understanding and knowledge sufficient to read knowledgeably popular accounts of research in the field (e.g., newspaper reports, secondary science publications) and then towards being able to read primary accounts (e.g., scientific journal articles). These individuals in the previous two categories are able to use acquired knowledge to read 
primary and secondary reports from an expert community but have not had the discursive experience or developed the tacit knowledge required to interact and make judgements within that expert community.

It is socialization (especially socio-linguistic) that marks the transition from these categorizations - that could all be labelled as non-expert or public - to those that are considered expert. ${ }^{8}$ I have already noted the extreme end of the continuum as those with contributory expertise, but lying between contributory expertise and public primary source knowledge are those individuals with interactional expertise. These individuals have engaged deeply in the expert community and have developed the tacit knowledge typical of the area. While they may not contribute to knowledge generation, they understand and can use specialist language in appropriate ways and make their judgements based not just on acquired knowledge but on a cultural understanding of the area of research. Collins and Evans note that to facilitate true recognition of non-scientific experts, these experts should ideally have interactional expertise in the related area of science and that the scientific experts should have the appropriate interactional expertise to engage with the non-scientific experts.

This approach, and in particular Collins and Evans justification, is not without its critics ${ }^{10}$ but there is relevance in this definition of expertise as a way of approaching participation and engagement in public debates and discussions because recognizing some who would otherwise be labelled "lay" as "expert" implies that they no longer speak for the relevant publics but instead also speak to them, as expert scientists do. They are therefore implicated in the larger project of science communication. This implication is one of the key reasons why newspaper comments have been chosen for this study. There are other fora set up precisely to facilitate engagement between scientific and personal experts (e.g., websites such as Patients Like Me, ${ }^{11}$ GalaxyZoo $^{12}$ ) but these discussions serve different purposes, they are not spaces for communication with or in view of wider publics. I am interested here in how these experts present themselves and are recognized by each other and by non-experts in openly public and widely accessed fora.

\section{Boundary work}

A key question to ask then is whether the proposed vertical boundary holds up to the boundary-work of credentialed scientific insiders. The term boundary work refers to efforts directed at achieving and maintaining credibility for science and scientists. ${ }^{13,14}$ It occurs in any situation where claims to expertise and cognitive authority are validated and challenged and where individuals from different communities would contend for that authority. Note that Gieryn originally used the term boundary work to describe how some scientists work to include or exclude other scientists or pseudoscientists and traces its history to the boundary work done to distinguish science from religion and technical pursuits. By invoking experience and expertise as part of the boundary work, however, the idea translates well to efforts to understand interactions between those who might be seen to have the relevant expertise to contribute to and evaluate research in a public forum and those who do not. Analogously to pseudoscience and religion, the knowledge of non-scientific experts is normally dismissed as lying outside of the boundary of valid and appropriate scientific knowledge. ${ }^{15,16}$

In public debates, Moore and Stilgoe propose the use of anecdotal evidence as a key site in the negotiation of boundary and expertise. ${ }^{17}$ Anecdote is a typical form for expressing the expert knowledge that individuals have of their own bodies and how those bodies react to medication ${ }^{18,19}$ or the immediate environment and context of their lives and work. ${ }^{20}$ Anecdotes and anecdotal evidence are, however, typically narrative in structure and have the individual at the centre of the narrative. They lack the linguistic markers of typical scientific language. ${ }^{21,22}$ This construction lends itself to classification as a subjective rather than objective form of knowledge. Anecdotes and anecdotal evidence are typically disputed and often outright rejected in debates of scientific issues, as illustrated in the following interview excerpt from Moore and Stilgoe's case study of public debates about mobile phone risks: "That's why you have science. It's to avoid anecdotes. It may be sensible in sociology, but if you want to know whether X causes Y, the fact you can find a person who has X and Y isn't evidence". ${ }^{23}$ This is an example of explicit boundary work that subverts the possibility of Collins and Evans's vertical boundary.

The question to be addressed here, then, is whether expertise expressed by individuals outside of science (typically in the form of anecdote) is proffered and, if so, how is it taken up in a public online environment. To avoid problematic terms such as "lay-expert" or "public-expert", the term personal expertise will be used here to describe this expertise arising out of personal experience rather than formal 
scientific training. This term also allows for the possibility that someone with scientific credentials may also have personal expertise in any number of areas. The expertise addressed in this paper is that which is claimed by individuals themselves. It will be considered personal expertise if the individual supports their expert status through reference to their personal experience. Similarly, scientific expertise will be noted where individuals support their claim to expertise though appeals to their scientific experience in the relevant area.

At this point, it is also important to ask why this question merits asking in online environment such as public comment spaces. What does the interaction of scientific and personal experts in online spaces have to offer to the understanding of scientific communication?

\section{Online science communication}

Commenting on scientific studies has long been part of traditional scientific discourse practices. Scientific journals have traditionally reviewed and published comments from other researchers regarding the findings, methods, and underlying theoretical approaches and justifications of studies published in that journal. The comments are reviewed by the editors of the journal (and sometimes peer-reviewed). ${ }^{24}$ This process is primarily accessible only to academic scientists because access to these journals requires either a personal subscription or access to an institutional subscription. The debate and discussion is peerto-peer in a literal sense: scientific expert to scientific expert. Similarly, in response to public scientific writing (e.g., articles in mainstream newspapers and secondary sources such as science magazines) some commenting ability has always been available to the reader but it was typically limited by the space available for letters to the editor. In general, a collection of letters addressing only a few recent topics could be selected for publication by the editors. And while there exists in this model a potential for mixing between scientific experts, personal experts and non-experts, there is little opportunity for letter writers to engage each other in debate or conversation and little opportunity to challenge or question who is recognized as "peer" or "expert". Online commenting opens up a new possibility for science communication: a peer-to-peer interaction where the qualification for peer status is negotiated and in part determined by the reactions of the other participants.

Internet communications in general have been the site of a sharp increase in the number and range of actors engaging in the communication of science or science-related information. ${ }^{25}$ Some of potential benefits of this increase include: the potential for collaborative learning and knowledge generation, enhanced civic engagement with scientific issues, and increased positive public relations opportunities. ${ }^{26}$ Parry, however, asks the important question of how scientists are negotiating the potential boundary threats implied by this increase in actors. ${ }^{27}$ On one extreme, some scientific discussion papers addressing online public communication of science are dominated by issues of correctness and expert opinion. ${ }^{28,29}$ Information from non-scientists takes on the spectre of threat rather than possible contribution. For example, Minol et al. argue that "formal and informal communication within the scientific community increasingly is overlaid with science communication which occurs in the public sphere and which, furthermore, is increasingly influenced by non-scientists. Consequently, it has become increasingly difficult to distinguish between 'correct' and 'false' information, or between reliable structured data and random information." 30 Furthermore, they suggest that "wisdom of the masses" approaches to the presentation of scientific information can only work when contributions are made primarily by experts. The problem, as they view it, is that in many online environments verifying the credentials of those who would qualify as experts is nearly impossible. These views emphasize an explicit boundary-work approach that privileges the expertise of those with scientific credentials.

One the other extreme, scientists have, in less formal venues, argued that the larger questions regarding online contributions relate to anonymity and identification as they impact the scientists themselves. ${ }^{31,32}$ Some argue that comment posting should ideally be completely anonymous, to allow the most forthright critical commentaries. ${ }^{33}$ Others counter that identification is important to provide incentives (such as institutional recognition) and prevent vandalism. ${ }^{34}$

The important assumption in these discussions, however, is that these scientists are referring to peer-topeer interactions between scientific experts. One participant noted that the "The people there [involved in particular online discussion] are both online_people, and experts, and interested in commenting on that particular article." ${ }^{\prime 35}$ The reader outside of science is not necessarily excluded, they are just not part of the factors under consideration. This suggests an implicit reference to boundaries, where readers are assumed 
to either all be appropriate experts or at least to have the ability to readily distinguish between expert commentary and vandalism. This is, however, a different environment and community than is served by scientific journalism in newspapers. Newspaper comment section present an opportunity for interaction not only between experts but also between experts and non-experts and between scientific experts and personal experts who may or may not have access to specialized fora. As such, they provide an ideal place for the examination of Evans and Collins vertical boundary.

\section{Methods}

This study examines expertise in the online comment community of a Canadian national newspaper with the goal of examining whether the dominant model is Collins and Evans's vertical expertise boundary or the traditional scientist/non-scientist boundary. Explicit claims to expertise from scientists and nonscientists were examined and the linguistic structure of the posts was explored for implicit cues to the expertise model being referenced.

The newspaper used for this study is a traditional newspaper with a long standing print edition as well as a well-established web presence. The science articles are written and posted by professional science journalists including both freelance and staff writers. The newspaper was one of the first in Canada to offer a comment space for readers and since its inception the comment community has become a vibrant and well-used service, with news articles receiving anywhere from five comments to over a thousand. The commenting feature is generally open for seven days after the initial posting of the news article. After this period, the comments are closed and the articles are moved to a subscription-based archive. The comment posts are moderated and those containing potentially offensive material or primarily ad hominem argumentation are removed by the moderators. There are no requirements for posting and responding to comments other than signing up for a free login account. The commenting feature is open to any and all interested readers internationally, although the vast majority are posted by users who identify themselves as Canadians.

As part of a larger study of public scientific discourse, over a four-week period each news article posted to the science, technology, and health sciences sections of the paper was downloaded (with the corresponding comments) twice: once as soon as the article was posted and once after a period of seven days (corresponding to the time just before the comments were closed and the article removed). The resulting collection included 27 articles with accompanying comments (ranging in size from five posts to over 650 per conversation). For this study of contributory expertise, these 27 articles were examined for topics where: a) there was sufficient posting to examine patterns (only those with more than ten comments were considered) and b) where there was a reasonable possibility of contributory expertise existing outside of credentialed scientists. This examination resulted in the selection of three articles related to the health sciences. Two addressed drug and treatment testing ("Peanut exposure reduces allergy"36 and "Canadians open door to learning-disorder drug, ${ }^{, 37}$ ) and one addressed an epidemiological study ("Attention-deficit disorder linked to obesity" ${ }^{38}$ ). Note that for this analysis, comments that did not address the scientific content of the article or relate in any relevant way to the issue being discussed (e.g., "Another example of Harper's Conservatives looking out only for the rich") were removed from the analysis.

The analysis began with identification of postings that appeared to represent claims to expertise (either personal or scientific). This identification rested on explicit claims (e.g., "I have a LD [learning disability] which affect both my writing (through to paper transfer) as well as information processing. I'm also well involved in the disabled community.") or implicit claims such as the use of technical language (e.g., "If obesity is included in the DSM - V, as is currently being considered, perhaps we will see more research into hormones and neurotransmitters that are involved"). After identifying these instances of expertise claims, the full comments were examined for other posts that were either generated in response to these expertise comments or for which the expertise comments were themselves responses. These conversations were gathered together for linguistic discourse analysis. This included noting word choice, grammatical structure and reasoning structure. Particular attention was paid to forms typical of science en $^{39,40}$ and to those typical of narrative and anecdote. ${ }^{41}$ Comparisons were made between each of the conversational episodes and between the episodes found in each of the articles. All quotes presented as part of this analysis are presented in their original form. Spelling and sentence structure have not been altered.

It is important to note that this analysis of expertise relies on individuals' self-ascribed expertise. Classifications were based on type of expertise that commenters invoked or claimed in their posts. Claims to 
either type of expertise could not and were not verified. Additionally, there may be commenters implicitly claiming scientific expertise (e.g., through the use of technical language) who are not scientists but instead other individuals with highly developed interactional expertise in science. Because they have chosen to present themselves through the lens of their interactional scientific expertise and not their personal expertise, they are classified here as representing scientific expertise. The goal of this study is to examine interactions based on the type of expertise claimed in a public forum and therefore the inability to verify the source of expertise is not seen as major hindrance. It should, however, be kept in mind.

\section{Findings}

The three topics covered by these articles (peanut allergies, learning disabilities, and attention deficit hyperactivity disorder) are frequently life-long conditions often diagnosed in early childhood. There are, therefore, at least two potential groups with the sustained experience necessary for the development of personal contributory expertise (patients and families of patients). These are also medical conditions with which a wide variety of health professionals and researchers may have expertise (e.g., physicians, psychologists, nurses, social workers and researchers in these fields). It was in part because of these assumptions that these articles were chosen over others in more esoteric fields. It is not a surprising then that in all three articles there were claims made both to personal expertise and to scientific expertise. See Table 1 for examples from each of the three articles.

\begin{tabular}{|c|c|c|}
\hline & Personal expertise & Scientific expertise \\
\hline $\begin{array}{l}\text { Attention-deficit } \\
\text { disorder linked to } \\
\text { obesity }\end{array}$ & $\begin{array}{l}\text { While I agree that a more thorough study needs to } \\
\text { be done, I am more disturbed by the severe } \\
\text { misunderstanding of what ADHD is. It is a } \\
\text { neurological disorder where a person is unable to } \\
\text { filter out distractions, usually has a lack of } \\
\text { inhibitions, exhibits jumpy thoughts, has a hard } \\
\text { time concentrating and finishing tasks, and may } \\
\text { fidgit. It is not a made up reason for drug } \\
\text { companies to sell drugs, nor is it due to a lack of } \\
\text { "fatherly" affection. ... both have ADHD and have } \\
\text { taught children with ADHD. It is a truly mixed } \\
\text { blessing, the worst part being the ignorance and } \\
\text { cruelty of people who assume you are just lazy, had } \\
\text { bad parents, stupid, and duped. }\end{array}$ & $\begin{array}{l}\text { Although co-morbidity is very common with many } \\
\text { diagnoses of mental disorders, there is no evidence } \\
\text { to suggest that people with eating disorders should } \\
\text { be screened for ADHD. ...In terms of eating } \\
\text { disorders, serotonin is actually the most often } \\
\text { implicated neurotransmitter, not dopamine as we } \\
\text { see in individuals with ADHD (Ritalin acts on } \\
\text { dopaminergic pathways). The hormones leptin and } \\
\text { ghrelin have also been linked to ED. If obesity is } \\
\text { included in the DSM - V, as is currently being } \\
\text { considered, perhaps we will see more research into } \\
\text { hormones and neurotransmitters that are involved; } \\
\text { in the mean time, making comparisons between all } \\
\text { of these different conditions is speculative at best. }\end{array}$ \\
\hline
\end{tabular}

Table 1. Sample Comments Representing Personal Expertise and Scientific Expertise. 
Over the three articles, posts representing claims to either personal or scientific expertise made up between $20 \%$ and $30 \%$ of the posted comments. The remainder of on-topic posts were much less detailed and included comments based on "popular knowledge" or less substantiated opinion (e.g., "it could also be a medication for alzhimers patients, or generally the elderly who suffer from old age related cognitive difficulties"; "As George S says, many children with learning problems seem to have behaviour problems. There is evidence linking learning/behaviour problems in children to excessive viewing of TV and playing video games, due to parents abandoning a parental role in favour of being just friends to their children."). The focus of this paper, however, is on comments reflecting expertise and the responses to those comments. The remainder of the analysis will attend only to those identified as relating to personal or scientific expertise.

One key difference noted in the content of the expertise-related posts was that, in all cases, those posters that included sufficient or appropriate information such that a designation of personal contributory expertise could be considered also made explicit reference to the personal experiences through which they developed that expertise (e.g., "Speaking as someone who has a severe allergy to nuts...", "I both have ADHD and have taught children with ADHD", "Having a triplet boy with non-verbal learning disabilities has been heartbreaking"). In one instance where the author of a post did not provide such justification, others demanded justification for his claim to understand those with learning disabilities. He argued that many people did not want to be "fixed" and resented the implication, made in the article, that learning disabilities should be cured. In response, six different posters replied explaining their in-depth experience with learning disabilities and stating in various ways that he did not have the appropriate experience or expertise to make such claims: "I suspect you have never once in your life felt out of place, and have no idea what a person with a disability has to go through both physical, social, and mental challenges. I am positive you don't know what persons with disabilities want." They explicitly and implicitly asked him to defend his expertise status. He responded with a post that began with the following: "Okay for those out there that think I'm some ignorant $a^{* *}$ I'm not. I have a LD which affect both my writing (through to paper transfer) as well as information processing. I'm also well involved in the disabled community and it has been my experience that people tend to focus on their disabilities being a negative thing, and that it should be somehow fixed." This conversation illustrates the importance of explicit justification of experience when individuals are claiming personal expertise. Note also the typical narrative construction embedded in these claims to personal expertise and those features in Table 1. In most cases the authors of the posts are themselves the central subjects or characters in the sentences. The majority of sentences are active in voice and first person pronouns are prevalent.

In interpreting the claims to scientific expertise, on the other hand, it was rare for explicit claims to be made. Only two posts out of 234 included explicit mention of credentials or scientific experience. One poster identified himself as a physician and another as a doctoral student in a relevant area. In the remainder of scientific expertise posts, the classification of expertise had to be made based only on implicit factors such as language, vocabulary, and apparent knowledge of the field. As can be seen in the samples in Table 1, the posts classified as scientific expertise show typical markers of scientific language. Consider the following excerpt:

To me, these links are fairly unsurprising. One of the primary components of ADHD is there is some sort of defect causing insufficient activation of Dopaminergic and Noradrenergic postsynaptic receptors in the brain. It seems to be helped not just by stimulants, but by any substance that results in increased NE and DA availability, such as atomoxetine or bupropion, which both have different mechanisms of action than Methylphenidate and Amphetamine. Both of these substances have also been observed to encourage weight loss, without being stimulants like Amphetamine or Methylphenidate.

Not only does it include several examples of technical lexical terms (e.g., Dopaminergic), it exhibits the high lexical density typical of scientific writing. ${ }^{42}$ Also, like typical scientific writing, this lexical density is supported by nominalization. The nominal group "insufficient activation of Dopaminergic and Noradrenergic post-synaptic receptors in the brain" is a particularly dense and lengthy example. There is also a high density of subordinate clauses (especially in the third sentence) and an emphasis on the passive voice (e.g., "It seems to be helped..." and "have also been observed"), other constructions typical 
of the language associated with scientific expertise. ${ }^{43}$ From a narrative perspective, this post has little in common with those of a primarily anecdotal or narrative construction. ${ }^{44}$ For example, there is only one use of a personal pronoun (me, used in the first sentence) and the central "character" or subject of the only other non-passive sentence is non-human ("some sort of defect" in the second sentence).

This construction is typical of the scientific expertise posts. And while there were few explicit claims to scientific credentials or experience (and as mentioned above, these credentials cannot be determined from data available here), one poster in the peanut allergy article made the explicit connection between formal scientific training and the ability to understand and discuss these scientific issues appropriately: "To become fully conversant with what is currently known about the immune system you would be looking at about 3 years of full time study (by which time some of the material from the beginning of the course would be outdated)." This comment supported the use of scientific language as a marker of claims to scientific expertise for the purposes of this analysis.

Examining the conversations surrounding those posts that claimed scientific expertise revealed another area of contrast. Not only were explicit statements of credentials absent, other posters did not demand justification of scientific credentials or experience. Instead, they themselves conformed to the discursive norms of science and asked for citable references and substantiated evidence of the claims made in individual posts. For example, "Dr. T, Can you at least post a link or another source that backs up your story? An anonymous quote saying 'this is just plain wrong' really doesn't persuade anyone." To which Dr. T responded: "You're quite right. The British Medical Journal has been running a series of interesting Comments under the heading For and Against: Are the dangers of childhood food allergy exaggerated? www.bmj.com/cgi/content/full/333/75".

Interestingly, however, typical scientific discursive construction was not isolated to posts claiming scientific expertise. In many cases, posters explicitly claiming personal expertise also exhibited scientisation in their contributions. Scientisation refers to the use of language to focus a discussion on technical, rather than social or ethical, aspects of a phenomenon. ${ }^{45}$ It is often considered a form of boundary work and can be accomplished through the use of technical rather than everyday terms, the use of typical scientific language structures, and an emphasis on objective rather than subjective aspects. While all of the posts classified as exhibiting personal expertise have, to a certain degree a narrative and anecdotal construction (as noted above) they also have a high lexical density, like those exhibiting scientific expertise. For example, the three excerpts in Table 1 have densities of 3.5, 6.25 and 5.8 respectively. These are much closer to the typical values that Halliday reports for scientific writing (densities typically around 6) compared to everyday writing (densities typically around 2). They also include technical lexical terms (e.g., "neurological disorder", "lack of inhibitions", "anaphylaxis", "scleroderma", "mastocytosis") and typical scientific structures such as nominalization ("serious levels of discrimination within the medical community itself") and passive voice ("the mistake being made in regards to many of these disorders", "a reaction response is triggered"). Overall, this scientific language was present to a much lesser degree than in the comments of those classified as scientific experts. Finding even this degree of scientisation, however, contradicts arguments from the literature that anecdote is the primary communication tool for personal expertise. These scientised posts also contrasted posts that do not exhibit either personal or scientific expertise. These were predominantly written in informal and everyday language (e.g., "Like most so-called medical breakthroughs I suspect this research will probably end up nowhere eventually.").

Parry suggests scientisation as a strategy employed by scientists to engage in boundary work between themselves and those outside of science. ${ }^{46}$ In her case study, it is a strategy used to attempt to maintain cognitive authority over those in various publics who are perceived to misunderstand scientific cloning (and other controversial topics) due to the social and ethical lenses through which they approach these topics. It is possible here, that scientisation is also a boundary work strategy for individuals with personal expertise seeking recognition as experts and attempting to place themselves inside the expert/non-expert boundary by appearing more scientific. They are perhaps engaging in the development of scientific interactional expertise

There is some evidence in these comments that it is a worthwhile strategy. In most of the examples of interaction between posters, especially those examples that involve prolonged dialogue and multiple dialogue participants, almost all of the participants exhibit or claim the same type of expertise. For example in the learning disabilities drug article there is conversation between five posters with personal expertise discussing their experiences with various treatments. Similarly, in the attention deficit and 
obesity article there is a conversation between four scientific experts addressing methodological issues. In the peanut allergies article, however, there is a discussion that begins with the following highly scientised example of personal expertise. It was written in response to a posted question regarding whether allergies can be triggered by scent:

First, a person can be allergic to smells. A triggering scent can set off full blow anaphylaxis and is life threatening. Auto-immune illness sufferers are most prone to this. However, peanut and other allergy sufferers can definitely be triggered by a scent. The allergy response is triggered by mast cells. Some people have too many mast cells or defective mast cells, which makes their allergies more severe. In a normal, healthy person, a sneeze occurs because an irritant invades the body so the mast cells degranulate, dumping histamine and other chemicals into the bloodstream, which provokes the allergic response. ...Some adults develop these allergies purely due to defective mast cells and excessive degranulation. The main disorder associated with mast cells is called mastocytosis.

You will all be very happy to know that those of us with mastcytosis tend to live very restricted lives already. Part of it is because we're so ill we have no other choice. Part of it is also because the world is full of things which can kill us, so yes, we don't eat much if at all, we don't go out in the world a lot, and we have to be exceedingly careful. Those of us who suffer with these allergies and illnesses which mimic allergies (but are not true allergies) are very understanding of the limitations our illnesses impose on others. However, beating us up for being sick and making your life inconvenient is a sad comment on our society today.

This example illustrates a thorough balance between scientific language and grammar and the narrative orientation of personal writing. In response, eight different posters engage in a discussion that includes both purely anecdotal accounts and purely technical explanations. It is the best example of true engagement between both scientific and personal experts evident in the comments sections of these three articles. Because it is a single example, a causal attribution cannot be made but I would hypothesize, based on the contrast between the initial posts in this conversation and those of the exclusively everyday and exclusively scientific conversations, that scientisation and interactional expertise is a key factor in engagement between different types of experts. It is noteworthy to mention that a poster in the same article, categorized as holding scientific expertise, appeared to attempt to engage in interaction with the personal experts and others through the use of a hypothetical anecdote. This attempt was much less successful than the scientisation attempt above: His or her anecdotal post post did not receive any responses.

Related to this finding was the noteworthy value that posters explicitly placed on the contributions of those with scientific expertise and scientised accounts of personal expertise. Within the comments on the ADHD and obesity article were three posts that directly recognized the value of the scientific contributions of the other posters. (e.g., "With perhaps one or two exceptions, I never cease to be amazed at how much more informed and statistically literate the posters on G\&M are than the journalists themselves. My only hope is that the writers read these comments and build up a better understanding of how to interpret clinical studies and health claims. Or, that the readers don't skip past the comments and take these claims at face value"). No such explicit comments were made about the value of the personal expertise contributions.

\section{Discussion and conclusions}

In these comments, both types of expertise are well represented. Commenters are implicitly and explicitly claiming both personal and scientific expertise. Evans and Collin's assertation that expertise exists outside of the scientific community is supported. Scientific language and grammar is, however, prevalent overall. It is the main mechanism for claiming scientific expertise, with explicit claims to credentials being rare. More surprisingly it is also common in the comments containing explicit claims to personal expertise. And while scientific language does not seem necessary for claiming personal expertise (commenters demanded that these claims be supported by evidence of experience) engagement between different types of experts and between personal experts and non-experts seems potentially to be facilitated by scientisation. In the three articles we also see that the interaction appears to fall along traditional peer-to-peer boundaries: scientific peer to scientific peer and personal peer to personal peer. 
From the perspective of a non-expert reader, both are present and, as the literature suggests, the comments offer the opportunity for exposure to both; both scientific and personal experts have the opportunity to speak to various publics. But the conversations show little evidence of a more open expertpeer to expert-peer dialogue where scientific experts and personal experts can be peers. It shows us that achieving open dialogue between both types of experts in the public view requires more than just opportunity and a venue.

The guiding research question for this study was whether given the public nature of these online comment environments and the opportunity that they offer for engagement between a) those with scientific expertise and those with personal expertise and $b$ ) between these experts and non-experts, does this engagement happen in ways that support Evans and Collins vertical boundary? Is the distinction between expert and non-expert the traditional boundary of scientific credentials or is it one that recognizes different types of expertise, both personal and scientific? In a sense, it is neither. The lack of explicit invocation of scientific credentials might suggest that they are not the salient marker between scientific insiders and scientific outsiders in a mostly anonymous public forum like this. In this situation it is the socio-cultural aspects of science that come to the forefront. It is those with interactional expertise in science (however acquired) that are seen and responded to as experts and it is this ideal that personal experts are potentially striving for in scientising their language. Fox, Ward and O'Rourke found a similar paradox in their examination of an online support forum related to an obesity drug. The site encouraged the concept of "patient expert" but that expertise was enacted by the participants in ways that reinforced medicalized views of obesity. ${ }^{47}$ This language-defined boundary is also not entirely divorced from credentials as at least one poster noted the importance of scientific training in develop interactional expertise. Further research is needed to probe whether readers and other commenters are making a similar assumption. Are they accepting scientific language as a marker of expertise because they believe it can only be attained through scientific training?

In conceiving this study I envisioned the possibility of two separate expertise continua, recognizing the expert status of those with personal and scientific experience. Figure 1 illustrates these possible continua, with (a) illustrating the conventional boundary line between those with scientific credentials and those without. In contrast, (b) illustrates Evans and Collins proposed vertical boundary that recognizes those with extensive experience (either scientific or personal) as experts. This public online comment medium was seen to have potential to support these two separate continua and the vertical boundary. The analysis presented here suggests that the vertical boundary does appear to apply to a certain degree, in that both types of expertise are recognizable in the comments. The language analysis, however, suggests that there is only one salient continuum - that of scientific expertise. Those with personal expertise are seen to engage in positioning work to move themselves onto the scientific continuum and inside that boundary through the use of scientised discourse patterns. Other experts, who do not explain the source of their expertise, consistently claim and position themselves (also through language) on the scientific expertise continuum. Within this environment, the possibility of peer-to-peer interaction between scientific and personal experts is not realised.

Several important questions emerge from this analysis. First, what is the implication of the apparent requirement for personal experts to scientise their discourse? Learning the discourse conventions of science can be difficult. ${ }^{48,49}$ Research in science education suggests that difficulties in reading, writing and speaking scientifically is challenging and can block students' abilities to be recognized by peers and teachers as science students. ${ }^{50}$ Is there a similar mechanism here, where those with relevant personal expertise may not have their voices heard meaningfully because they are unable to appropriately scientise their communications? If so, who is excluded - those with lower levels of education, those with general literacy difficulties, and people from economically disadvantaged communities? By choosing online comments, this study already only includes those with computer and internet access as well as time and interest to read health science studies and comment on them. But if the patterns seen here are more generalized (a question for further research) then it suggests even more strongly that personal expertise is not recognized. The meaning of personal expertise is that it is developed through life experience. A situation that recognizes only those able to attain and present their experience using particular discourse strategies undermines this definition. Second, is there another side to this? Is the scientisation of language seen as appropriate (by both types of experts) as a type of boundary work that is appropriate for both expertise continua? At least in the case of health issues, is some engagement with scientific language (possibly necessarily for navigating treatments or hospital visits) another way of illustrating the personal 
experience at the heart of personal expertise? Does it help both types of experts sort out reliable expert information from non-expert opinions? The data presented here cannot answer these questions but it does provide a base for examining this issue further.

(a)

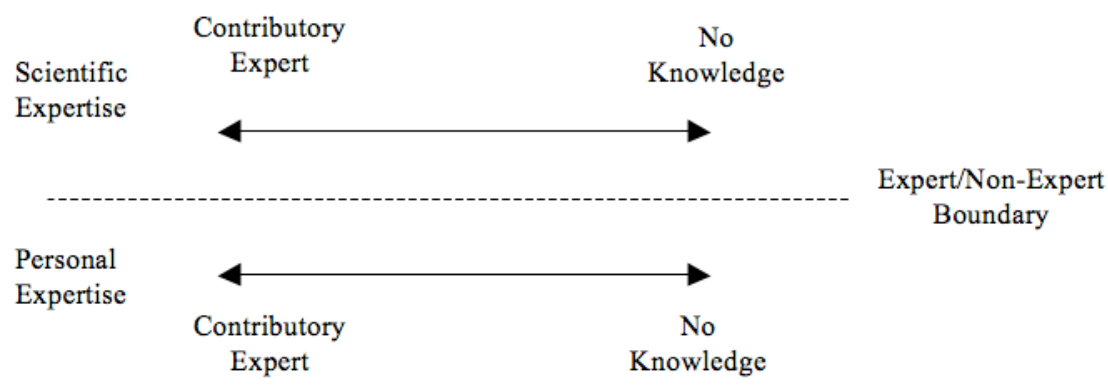

(b)

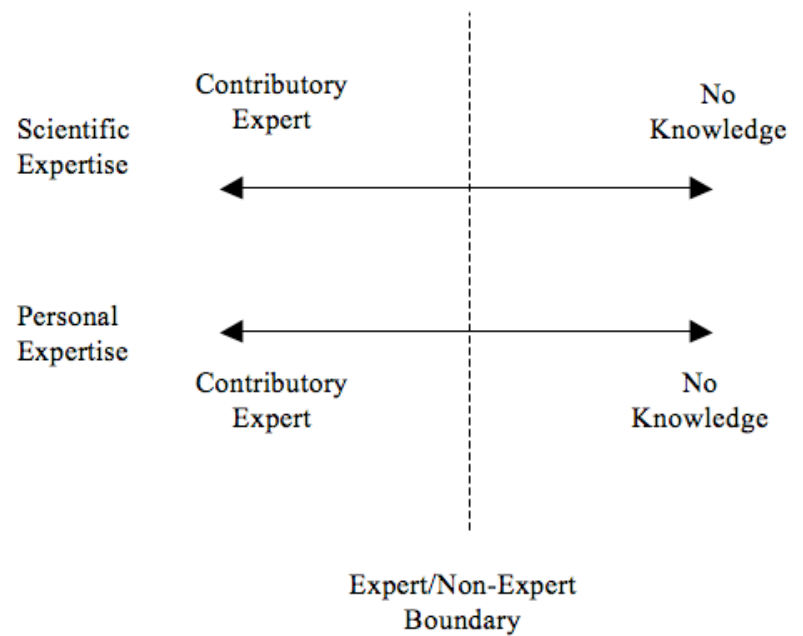

Figure 1. (a) Two expertise continua divided by the conventional scientist/non-scientists boundary (b) The same two continua divided by Collins and Evans proposed vertical boundary.

An additional (and related) question, is whether it is desirable to work to change this situation. And, if the answer is yes, how can that be accomplished? As the poster above noted, there is value for any reader in attending not only to the news article but also to the posted comments. This suggests that these comments are becoming part of the canon of scientific communication. Public reports of science may now be considered to include both the published and public aspects. If this is the case, what responsibility do journalists, writers and others professionally engaged in science communication have in shaping these discussion environments? Should they be responsible for encouraging different types of peer-to-peer interaction in response to their work? The results of this study suggest that these questions bear careful consideration both empirically and theoretically.

\section{Acknowledgements}

I am very grateful to two anonymous reviewers for their insightful and valuable comments on this manuscript.

\section{Notes and references}


${ }^{1}$ H.M. Collins and R. Evans (2002), The third wave of science studies: Studies of expertise and experience, Social Studies of Science 32(2): 235-296.

2 R. Evans and H. Collins (2008), Expertise: From attribute to attribution and back again? in E. J. Hackett, O. Amsterdamska, M. Lynch and J. Wajcman (eds.), The handbook of science and technologies studies, Cambridge MA, MIT Press, pp. 609-630.

3 R. Evans and A. Plow (2007), Listening without prejudice?: Re-discovering the value of the disinterested citizen, Social Studies of Science 37(6): 827-853.

4 R. Evans and H. Collins (2008); see 2.

5 H.M. Collins and R. Evans, Rethinking expertise, University of Chicago Press, Chicago U.S.A.

${ }^{6}$ R. Evans and H. Collins (2008); see 2.

7 R. Evans and A. Plow (2007), see 3.

8 S. Parry (2009), Stem cell scientists' discursive strategies for cognitive authority, Science as Culture 18(1): 89-114.

9 H.M. Collins and R. Evans (2002), see 1.

${ }^{10}$ B. Wynne (2002), Seasick on the third wave? Subverting the hegemony of propositionalism: response to Collins \& Evans (2002), Social Studies of Science 33(3): 401-417.

${ }^{11}$ PatientsLikeMe Inc. (2005)-(2009), http://www.patientslikeme.com.

${ }^{12}$ Galaxy Zoo (2009), http://www.galaxyzoo.org.

13 T.F. Gieryn (1983), Boundary-work and the demarcation of science from non-science: strains and interests in professional ideologies of scientists, American Sociological Review 48(6): 781-795.

${ }^{14}$ T.F. Gieryn (1999), Cultural boundaries of science: credibility on the line, University of Chicago Press, Chicago U.S.A.

${ }^{15}$ M. Aitken (2009), Wind power planning controversies and the construction of 'expert' and 'lay' knowledges, Science as Culture, 18(1): 47-64.

${ }^{16}$ S. Parry (2009), Stem cell scientists' discursive strategies for cognitive authority, Science as Culture 18(1): 89-114.

17 A. Moore and J. Stilgoe (2009), Experts and anecdotes: the role of 'anecdotal evidence' in public scientific controversies, Science Technology Human Values 34(5): 654-677.

${ }^{18}$ H. Arksey (1994), Expert and lay participation in the construction of medical knowledge, Sociology of Health and Illness 16(4): 448-468.

${ }^{19}$ L. Monaghan (1999), Challenging medicine? Body building, drugs and risk, Sociology of Health and Illness 21(6): 707-734.

${ }^{20}$ J. Popay, G. Williams, C. Thomas and T. Gatrell (1998), Theorising inequalities in health: The place of lay knowledge. Sociology of Health and Illness 20(5): 619-644.

${ }^{21}$ M.A.K. Halliday (1997), On the grammar of scientific English, in J.J. Webster (ed.), The language of science, pp. 181-198, London: Continuum.

${ }^{22}$ M.A.K. Halliday (1998), Things and relations: regrammaticizing experience as technical knowledge, in J.R. Martin and R. Veel (eds.), Reading science: Critical and functional perspectives on discourses of science, London: Routledge.

${ }^{23}$ A. Moore and J. Stilgoe (2009); see 17, p. 660.

${ }^{24}$ Science (2009), Information for authors, retrieved October 10, available at http://www.sciencemag.org/about/authors/.

${ }^{25} \mathrm{~K}$. Minol et al. (2007), Portals, blogs and co.: the role of the Internet as a medium of science communication, Biotechnology Journal 2(9): 1129-1140.

${ }^{26}$ A. Ashlin and R.J. Ladle (2006), Environmental science adrift in the blogosphere, Science 312(5771): 201.

${ }^{27}$ S. Parry (2009); see 8.

${ }^{28}$ K. Minol et al. (2007); see 25.

${ }^{29}$ A. Ashlin and R.J. Ladle (2006); see 26.

${ }^{30}$ K. Minol et al. (2007); see 23, p. 1130.

${ }^{31}$ W. Gunn (2009), Online Engagemen5 of Scientists with the literature: anonymity vs. ResearcherID, Retrieved from

http://synthesis.williamgunn.org/2009/05/24/online-engagement-of-scientists-with-the-literature-anonymity-vs-researcherid/

${ }^{32}$ Coturnix, 2009, Commenting on scientific papers, Retrieved from

http://scienceblogs.com/clock/2009/05/commenting on scientific paper.php.

${ }^{33}$ Genereg, 2009, May 24, Why people do not comment online articles? Comments posted to

$\mathrm{http} / / /$ friendfeed.com/science-2-0/9af350c1/why-people-do-not-comment-online-articles-what.

${ }^{34}$ C. Neylon (2009), May 24, Why people do not comment online articles? Comments posted to

http://friendfeed.com/science-2-0/9af350c1/why-people-do-not-comment-online-articles-what.

${ }^{35}$ Genereg, 2009; see 33.

${ }^{36}$ Peanut exposure reduces allergy, February 23 (2009), The Globe and Mail.

${ }^{37}$ C. Abraham (2009), February 24, The Globe and Mail, p. A1.

${ }^{38}$ M. Jimenez (2009), March 24, Attention-deficit disorder linked to obesity, The Globe and Mail, p. L1.

${ }^{39}$ M.A.K. Halliday (1997); see 21.

${ }^{40}$ M.A.K. Halliday (1998); see 22.

${ }^{41}$ M.G.W. Bamberg (1997), Positioning between structure and performance, Journal of Narrative and Live History 7(1-4): 335-342.

${ }^{42}$ M.A.K. Halliday (1997); see 21.

${ }^{43}$ Z. Fang (2006), The language demands of science reading in middle school, International Journal of Science Education 28: $491-520$.

${ }^{44}$ M.G.W. Bamberg (1997); see 41.

${ }^{45}$ S. Parry (2009); see 8.

${ }^{46}$ S. Parry (2009); see 8 .

${ }^{47}$ N.J. Fox, K.J. Ward and A.J. O'Rourke (2005), The 'expert patient': empowerment or medical dominance? The case of weight loss, pharmaceutical drugs and the Internet, Social Science \& Medicine 60:1299-1309.

${ }^{48}$ Z. Fang (2006); see 43.

${ }^{49}$ M.A.K. Halliday (1998); see 20. 
${ }^{50}$ B.A. Brown (2006), “It isn't no slang that can be said about this stuff'”: Language, identity, and appropriating science discourse, Journal of Research in Science Teaching 43:96-106.

\section{Author}

Marie-Claire Shanahan is an assistant professor of science education at the University of Alberta in Edmonton, Canada. Her research focuses on language and identity in science, including linguistic and sociological studies of science classrooms and sites of interaction between scientists and various publics. E-mail: mcshanahan@ualberta.ca.

How TO CITE: M.-C. Shanahan, Changing the meaning of peer-to-peer? Exploring online comment spaces as sites of negotiated expertise, Jcom 09(01) (2010) A01. 